Article

\title{
On the Burning of Plutonium Originating from Light Water Reactor Use in a Fast Molten Salt Reactor-A Neutron Physical Study
}

\author{
Bruno Merk ${ }^{1,2, *}$ and Dzianis Litskevich ${ }^{1}$ \\ Received: 4 September 2015 ; Accepted: 23 October 2015 ; Published: 5 November 2015 \\ Academic Editor: Hiroshi Sekimoto \\ 1 Helmholtz-Zentrum Dresden-Rossendorf, Bautzner Landstrasse 400, Dresden 01328, Germany; \\ d.litskevich@hzdr.de \\ 2 Center for Materials and Structure, University of Liverpool, Liverpool, Merseyside L69 3BX, UK \\ * Correspondence: b.merk@liverpool.ac.uk; Tel.: +44-151-794-4931; Fax: +44-151-794-4703
}

\begin{abstract}
An efficient burning of the plutonium produced during light water reactor (LWR) operation has the potential to significantly improve the sustainability indices of LWR operations. The work offers a comparison of the efficiency of Pu burning in different reactor configurations-a molten salt fast reactor, a LWR with mixed oxide (MOX) fuel, and a sodium cooled fast reactor. The calculations are performed using the HELIOS 2 code. All results are evaluated against the plutonium burning efficiency determined in the Consommation Accrue de Plutonium dans les Réacteurs à Neutrons RApides (CAPRA) project. The results are discussed with special view on the increased sustainability of LWR use in the case of successful avoidance of an accumulation of $\mathrm{Pu}$ which otherwise would have to be forwarded to a final disposal. A strategic discussion is given about the unavoidable plutonium production, the possibility to burn the plutonium to avoid a burden for the future generations which would have to be controlled.
\end{abstract}

Keywords: plutonium; plutonium management; plutonium burning; nuclear reactors; molten salt reactor (MSR); fast reactor; light water reactor; mixed oxide (MOX) fuel

\section{Introduction}

\subsection{The Plutonium Problem}

Today, almost all kinds of nuclear reactors are operated using ${ }^{238} \mathrm{U}$-containing nuclear fuel. Due to the unavoidable breeding processes higher isotopes are formed besides the production of energy and the formation of the fission products. Consequently, the operation of almost all kinds of nuclear reactors leads to the built-up of artificial isotopes like plutonium as well as other higher transuranium (TRU) isotopes. Most of the created artificial isotopes are characterized by very long radioactive half-lives, which have to be considered when a final disposal for the nuclear waste is designed.

"One of the greatest challenges in the use of nuclear energy is the highly radioactive waste which is generated during power production. It must be dealt with safely and effectively. While technical solutions exist, including deep geological repositories, progress in the disposal of radioactive waste has been influenced, and in many cases delayed, by public perceptions about the safety of the technology. One of the primary reasons for this is the long life of many of the radioisotopes generated from fission, with half-lives on the order of 100,000 to a million years. Problems of perception could be reduced to an essential degree if there were a way to burn or destroy the most toxic long-lived radioactive wastes during the production of energy" [1]. These are the words of Victor Arkhipov a consultant in the IAEA division of nuclear power and the fuel cycle, in the nuclear power technology 
development section given in an IAEA Bulletin in 1997. Following this arguments a very special focus should be given to the plutonium isotopes. On the one hand, these isotopes are by far the major share (more than $80 \%$ ) of the TRU isotopes. On the other hand, plutonium has the potential for the production of nuclear weapons. "A number of issues arise because of plutonium's potential use as an energy source and for the production of nuclear weapons.... Within 200 years, the protection afforded by intense radioactivity (spent fuel standard) will disappear as the result of the decay of most radioactive nuclides. If the spent fuel is buried in a geological formation, it might be regarded as a potential 'plutonium mine' meaning that at some later point in time the buried plutonium could be mined and extracted.... Without such reactors (fast reactors), spent MOX fuel will still end up in a final depository or in storage facilities. ... Are there any other methods for burning excess plutonium?" [2]. These sentences are taken from a contribution of Noboru Oi, a senior staff member of the IAEA Department of Nuclear Energy, published in the IAEA Bulletin on Comparing Energy Options in 1998. Already some years before a discussion has been started on the political level by the RAND Corporation (Santa Monica, CA, USA). In a publication on the accumulation of weapon-usable plutonium the problems arising from non-separated and separated $\mathrm{Pu}$ from nuclear reactors is discussed, too. "The concern of the former (non-separated $\mathrm{Pu}$ ) is that, eventually, the radiation from spent fuel will drop so much that national and subnational groups can reprocess the spent fuel quickly and easily for plutonium ... separated $\mathrm{Pu}$ is a more immediate and urgent issue, because the most difficult task of extracting $\mathrm{Pu}$ from the intensively radioactive spent fuel has already been performed; the remaining steps for incorporating the material into a nuclear bomb are much easier." [3]. The drop of the radiation level often call the decay of the self-protection level of Pu in the fuel is mostly dominated by the radiation level of the dominating fission products with intermediate half live time $\sim 30$ years. Consequently the radiation level drops to: $\sim 10 \%$ after 100 years and $\sim 1 \%$ after 200 years.

Recently, comparable concerns regarding the misuse of plutonium have been raised in the German P\&T study in the discussion of the chances of P\&T. "The application of P\&T on industrial level has the potential for a plutonium content in the final disposal which is negligible after the application of P\&T. Thus there is no risk of misuse and theft of plutonium (from the final disposal) anymore" $[4,5]$.

Already in 1996 a NATO advanced research workshop has been held in Moscow to discuss the problem of the plutonium management on a scientific level in an international group of experts. In the introduction given by Merz the risks arising from plutonium has been highlighted: "The lower content of the plutonium isotope ${ }^{239} \mathrm{Pu}$ in energy-grade plutonium, as well as the presence of a comparatively large amount of isotope ${ }^{240} \mathrm{Pu}$, make energy grade plutonium a less preferably material for nuclear munitions production than weapon-grade. Nevertheless, energy grade plutonium can be directly used for making a nuclear explosive device. All things being equal, the device will only be larger if it was made of weapons-grade plutonium" [6].

Generally, it can be concluded based on the different citations given above that a method for burning of the already existing and the in future in light water reactors (LWRs) produced plutonium is of high interest. The efficient and complete burning of the plutonium produced during LWR operation offers the potential to increase the sustainability of the LWR operation significantly. This can be stated at least for all countries which do not plan to switch their nuclear energy production capacities from the current park of LWRs to a significant park of fast reactors applying a closed fuel cycle, except from India which plans to build a significant number of fast reactors [7], no country envisages this large park of fast reactors currently. Only the efficient and root-and-branch burning of plutonium is the ultimate argument to avoid the risk misuse of plutonium in perpetuity.

One of the first promising coordinated scientific project on the burning of TRU isotopes and plutonium, especially, has been started in the early 90s in France-the Consommation Accrue de Plutonium dans les Réacteurs à Neutrons Rapides/Consommation Accrue des Dechets dans les Reacteurs RApides (CAPRA/CADRA) project, CAPRA—how to burn Plutonium, CADRA how to 
burn minor actinides. A short overview of the CAPRA project has been given by Languille et al. [8]: "During the first two-year phase (93-94) of the CAPRA Project studies, the feasibility of a Fast Reactor (FR) plutonium burner which also contributes to the destruction of Minor Actinides (MA) has been assessed for the oxide reference option based on a fuel plutonium content of about $45 \%$. The evaluation of this core of 1500 MWe was carried out covering different aspects: fuel behaviour, physics, and safety. Based on this evaluation, the feasibility of such a burner core is demonstrated. The heterogeneous concept of dilution provides a large flexibility to the core but a low fuel residence time".

Thus, the current level the fast reactor technology does not allow implementing of the fast breeder reactors for industrial scales of burning of plutonium. Therefore other optimized opportunities, such as molten salt fast reactors, can be taken into consideration.

\subsection{Why Molten Salt Reactors (MSRs)}

Already in 1992, in a technical note in the ANS journal Nuclear Technology based on their experience, Gat et al. [9] proposed the use of "Molten Salt Reactors (MSRs) for Burning Dismantled Weapons Fuel". In their abstract they summarized some really strong arguments which make MSRs highly interesting for the burning of plutonium: "The Molten-salt reactors have the flexibility to utilize any fissile fuel in continuous operation with no special modifications, as demonstrated in the Molten Salt Reactor Experiment (MSRE), while maintaining their economy. The MSRs further require a minimum of special fuel preparation and can tolerate denaturing and dilution of the fuel. Fuel shipments can be arbitrarily small, which may reduce the risk of diversion. The MSRs have inherent safety features that make them acceptable and attractive. They can burn a fuel type completely and convert it to other fuels. The MSRs also have the potential for burning the actinides and delivering the waste in an optimal form, thus contributing to the solution of one of the major remaining problems for deployment of nuclear power". The inherent safety features are based on the strong feedback effects in molten salt fast reactors (MSFRs).

The major effect, the salt density effect is strongly negative in all cases, due to the unity of coolant and fuel in a MSR. A decrease in the salt density due to a temperature increase coincides with a decrease of the density of the fissile material dissolved in the salt in the control volume. Thus the MSFR is a very stable system with strong feedback effects which inherently tend to stabilize the reactor at the given power level. The flexibility of the reactor for the use of different fissile materials has been demonstrated by the smooth transition from the ${ }^{235} \mathrm{U}$ startup core of the MSRE to the core fully operated on ${ }^{233} \mathrm{U}$ in the first months of 1969 . This was the first time ${ }^{233} \mathrm{U}$ had been used as a reactor fuel [10].

Already in 1978 Engel et al. [11], highlighted one of the most attractive features of liquid fueled reactors. When the plutonium or other fissile material is once put into a molten salt reactor system it is not necessary to separate the material in any of the steps of the burning operation anymore. This is a strong advantage which is in strong contrast to the fuel management like it is to be applied for any kind of solid fueled reactor with the separated steps of reprocessing, fuel production, and fuel irradiation. Unfortunately, in most of the cases, the different steps can even not be conducted at one site. Thus there are transports required between the sites. In a follow up publication, the authors discussed the reduction of the proliferation risk as one important aspect in the burning of plutonium to achieve a reduction of the plutonium amounts in the nuclear waste of LWRs. "MSRs, because of the fluid nature of the fuel, appear to provide an attractive approach to efficient fuel utilization in the thorium- ${ }^{233} \mathrm{U}$ cycle as well as a means for limiting the availability of plutonium and the general proliferation risks associated with nuclear power generation. ... the plutonium (most of which is consumed in situ) would be of poor quality and would never be isolated from all other undesirable nuclides. Thus, such systems would provide for efficient utilization of uranium resources in a proliferation-resistant environment while limiting the amount of plutonium (and transplutonium actinides) that would have to be handled as waste" [12]. 
A very detailed analysis and comparison of the general features of sodium cooled fast reactors and MSRs with the special view on the transmutation of TRU isotopes has been given at the international conference on fast reactors and related fuel cycles: safe technologies and sustainable scenarios (FR13), Paris [13] and later extended [14]. In these publications clear operational as well as safety and efficiency advantages of MSRs are carved out.

A presentation on the possible application of MSRs for burning of plutonium has already given at the mentioned NATO workshop in Moscow. The authors highlighted the possibility of an "all in one" solution and the flexibility of the system for the use of different fuels, too. "The advantages of the MSR as a burner reactor follow not only form a possibility for its combination with the gas-fluoride technique of fuel reprocessing, which is low-cost and produces a small quantity of waste, but also from its capability to use fuel of any nuclide composition without $\mathrm{Pu}$ purification from MA and FP. The MSRs have the flexibility to utilize any fissile fuel in continuous operation with no special modification of the core as demonstrated during MSRE operation for U3, U5 and Pu" [15].

From the point of view of the complete nuclear fuel cycle, MSRs have been a part of the U.S. study on Comprehensive fuel cycle options. In the study some really interesting and important effects have been carved out in the comparison with different other kinds of reactors. " ... when a MSR is adopted as the AE (Analysis Example) of a specific EG (Evaluation Groups), the material loss fraction was assumed to be lower than that of the common assumption because the molten-salt fuel is continuously reprocessed in an online mode.... Even though uniform assumptions for losses were used, the exception of having to specify losses for an MSR differently $(0.2 \%$ rather than $1.0 \%)$ caused the AE of EG26 to have the highest (fissile material) utilization because the exception resulted in the lowest material losses being assumed for the MSR that was utilized as the AE of EG26" [16]. These assumptions result in the best natural resource utilization in the whole study. Additional facts to be highlighted are: No spent nuclear fuel is created in MSRs for EG26 in the analysis and no depleted uranium, no non-used recovered uranium, and no recovered thorium mass will be created; only high level waste in the form of fission products is left over. This leads to the lowest over all waste mass for MSRs in the analysis of the Comprehensive Fuel Cycle Options launched in the U.S. in 2010 [16].

Summarizing the citations given above, the following conclusions can be made concerning the advantages of the molten salt fast reactor technology:

- flexibility to utilize any fissile fuel in continuous operation

- minimum of special fuel preparation

- arbitrarily small fuel shipments

- inherent safety features

- limitation of the plutonium availability and reduction of the risk of proliferation

- possibility of combination with the gas-fluoride technique of fuel reprocessing

- possibility to use fuel of any nuclide composition without plutonium purification from minor actinides and fissile products

- fissile material which is once inserted is not needed to be taken out anymore.

All these excerpts together demonstrate the high attractiveness of the MSR technology for the application as plutonium or TRU burner for the major objective of an economic and efficient burning process. Exactly these objectives are the key points for the already mentioned required increase in the sustainability of the LWR operation achieved by an efficient and complete burning of the plutonium produced during LWR operation.

\subsection{Development of MSRs}

MSRs have a long history, based on a, somewhat curious idea, developed in the early phase of the nuclear development. In the late 40 s and early 50 s the project of the nuclear aircraft has been investigated. This idea led to the Aircraft Reactor Experiment, a small thermal reactor (2.5 MW) [10]. 
The first small scale experiment has been followed by a larger one, the MSRE with 8 MW thermal. "Design of the MSRE started in the summer of 1960 and construction started 18 month later, at the beginning of 1962. The reactor went critical in June 1965, and was briefly at full power a year later" [10].

Recently, the MSR technology has attracted some new interest. Many countries worldwide contribute to MSR technology, among which are the United States, the Russian Federation, the European Union, France, Japan, India and for the past few years China and Korea. In Europe interest has been focused in the EURATOM project MOST-review on MSR Technology $[17,18]$. Following the MOST project, in 2010, two projects on MSR were selected and funded by European and Russian Agencies: the European Project: "Evaluation and Viability of Liquid fuel fast reactor systems" (EVOL) [19-21] and the Russian Project: "Minor Actinides Recycling in molten salts" (MARS) [22-24]. A three-year Euratom-Rosatom collaboration has been established, through the parallel coordinated projects (MARS-EVOL) on MSR [25]. In contrast to the historic MSRE, the objective of the new projects is the development of a molten salt reactor with fast neutron spectrum. This is achieved by omitting the graphite which has been used for moderation in the MSRE. The major argument, for the change in the neutron spectrum, is the improved sustainability indices. The MSRs are planned to be suitable for power production and either for breeding or for the transmutation of actinides from spent nuclear fuel.

\section{Materials and Methods [26]}

\subsection{Reference Configurations}

\subsubsection{Molten Salt Fast Reactor (MSFR)}

The calculation for the MSFR is based on the core dimensions and the boundary conditions given in the EVOL benchmark definition (see Figure 1). The reference core is a MSFR with $3000 \mathrm{MW}_{\text {th }}$ and a fast neutron spectrum. In this first approach the core is a single cylinder. The nuclear reactions occur within the flowing fuel salt inside the cylinder [27]. The dimensions are shown in Figure 1. The core is composed of four volumes: the active core, the upper extraction area, the lower injection area, and the out of core area with the heat exchanger and the pumps.

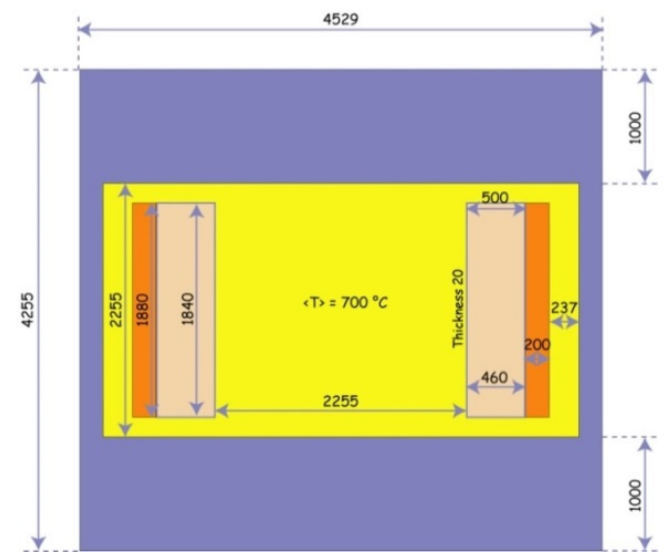

(a)

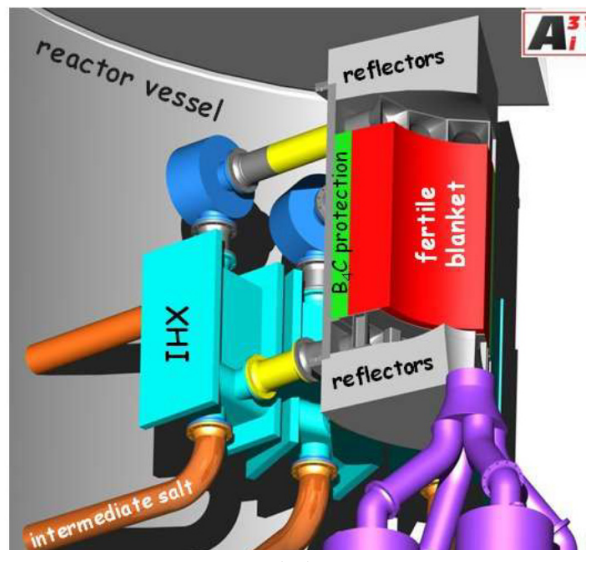

(b)

Figure 1. (a) simplified scheme of the circular molten salt fast reactor (MSFR) system (side view) including the core, blanket and intermediate heat exchangers (IHX); (b) benchmark definition [27].

For the simulations, the HELIOS 2.1 code is used [28]. The benchmark configuration is transferred to a volume corrected 2D circular HELIOS model (see Figure 2) which is adapted to 3D using a buckling correction available in HELIOS (BSQ: 0.00002). The value has been fixed by 
a comparison of 2D and 3D calculations within the EVOL benchmark exercises. The leakage in radial direction is directly modelled. Additionally, the model has been detailed compared to the EVOL benchmark configuration. The 16 heat exchanger pipes are resolved for a better representation of the real geometry.

The HELIOS code package is an industrial standard software which performs the neutron transport calculation, the burn up calculation, and if requested the cross section preparation in defined calculation areas. The code has been written for the simulation of solid structured fuel assemblies. Thus, the possibility of online refueling and online reprocessing is not foreseen. To deal with this special feature a PYTHON script has been developed, see Figure 3. All input data, which is constant during the whole reactor operation, is stored in an expert input. The changing material configuration is given in the user input which is written new in every cycle using the PYTHON script. Within each cycle five burnup steps of $1000 \mathrm{MWd} / \mathrm{tHM}$ at a power of $143 \mathrm{~W} / \mathrm{g}$ are calculated in one HELIOS run. Both inputs are merged in the pre-processor AURORA. The results are finally evaluated for each cycle in the post-processor ZENITH. Here it is decided which isotopes will be fed back into the next user input. Theoretically, this scheme could simulate the feeding process accurately by using small time steps. Two different time scales are modelled for the salt cleanup. These are the helium bubbling for the gaseous and the volatile fission products (these fission products are not considered when a new cycle is started, thus all fission products are taken out of the system after $5000 \mathrm{MWd} / \mathrm{tHM}$ ) and the online salt cleanup for the dissolved fission products (only $16.6 \%$ of the general soluble fission products and 15\% the lanthanides are taken out at the end of the cycle, the rest is carried forward via the script to model the permanent presence of a part of the fission products). A more detailed description of the modelling is given in [29].

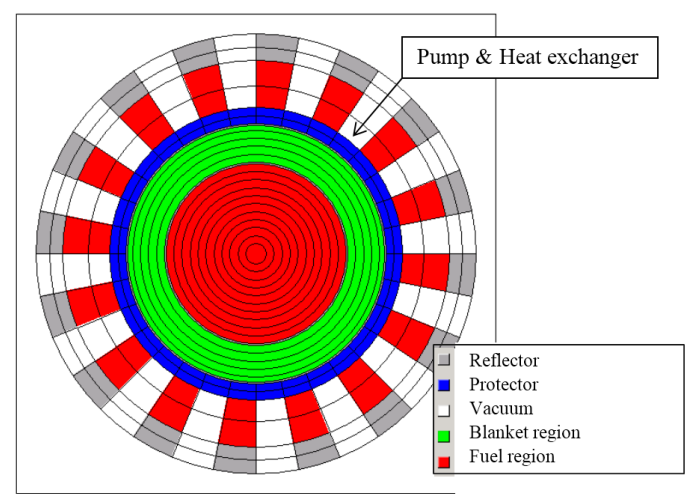

Figure 2. Volume corrected 2D circular HELIOS model of the molten salt reactor (MSR) (top view of the reactor).

One of the salt configurations and the corresponding thermodynamic data of the molten salt actinide recycler and transmuter (MOSART) project [23] is used, $17 \mathrm{LiF}-58 \mathrm{NaF}-25 \mathrm{BeF}_{2}$ (mole $\%$ ) mixed with $\mathrm{TRUF}_{3}$, which has been developed for the use in a fertile free system. The salt composition in the fertile region is pure $\mathrm{LiF}$.

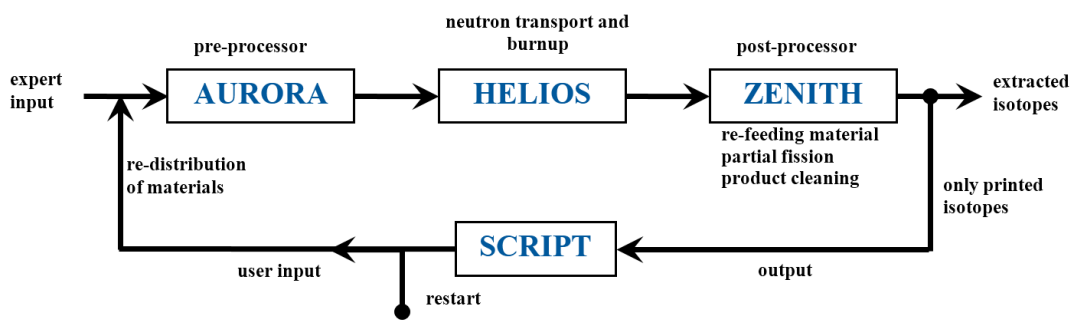

Figure 3. Description of the calculation cycle for the simulation of a MSR. 


\subsubsection{Sodium Cooled Fast Reactor (SFR) Fuel Assembly}

The calculations for the fast reactor configuration are carried out only on fuel assembly level like it is standard in solid fueled reactor systems for the preparation of the cross sections for the following full core calculations. The fast reactor fuel assembly model is derived from the data for the European Fast Reactor. The data is mostly given in the IAEA Fast Reactor Database-2006 Update [30]. Additional data has been taken from the textbook Waltar, Reynolds: Fast Breeder Reactors [31] and from the published European Fast Reactor (EFR) fuel assembly design [32], see Table 1.

Cladding, wrapper wire and can wall are made from stainless steel, SS 304 . The used material configuration definition is following the HELIOS definition [28]. The temperatures are: $635^{\circ} \mathrm{C}$ for the cladding, $545^{\circ} \mathrm{C}$ for the wrapper and the can wall, and $1100{ }^{\circ} \mathrm{C}$ for the fuel.

The modeled geometric arrangement of the reference system with 10 rings of fuel rods following the EFR design is shown in Figure 4 for $1 / 6$ part of one fuel assembly. The power density is set to $118.8 \mathrm{~W} / \mathrm{g}$ corresponding to the maximum power density in the EFR. The fuel assemblies contain $18.3 \%, 22.4 \%$, and $26.9 \%$ plutonium (depending on the core zone) and a burnup of $200 \mathrm{GWd} / \mathrm{tHM}$ is used for the comparison. The value $200 \mathrm{GWd} / \mathrm{tHM}$ has been chosen based on data from [8,33] as a typical for this type of reactor.

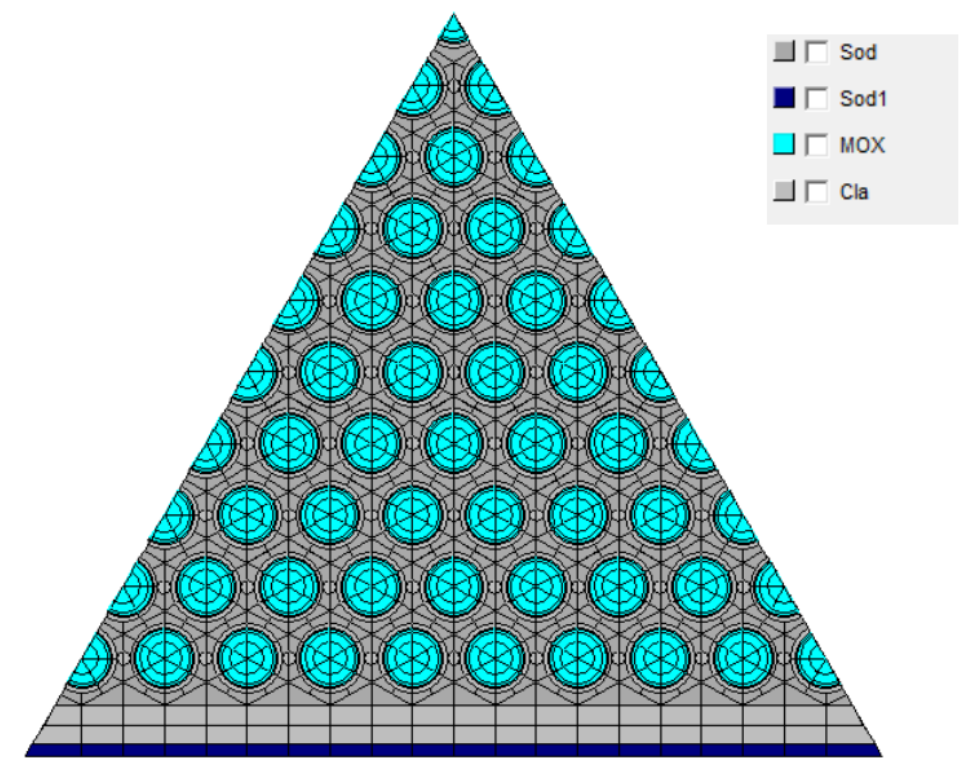

Figure 4. 1/6 of the sodium cooled fast reactor fuel assembly corresponding to the European fast reactor (EFR) geometry.

Table 1. Basic geometric data of the fast reactor fuel assembly.

\begin{tabular}{ccc}
\hline Component & Dimension & Unit \\
\hline Outer pin diameter & 8.5 & $\mathrm{~mm}$ \\
Cladding thickness & 0.52 & $\mathrm{~mm}$ \\
Pitch to diameter & 1.2 & - \\
Can wall thickness & 4.5 & $\mathrm{~mm}$ \\
Fuel density & 9.26 & $\mathrm{~g} / \mathrm{cm}^{3}$ \\
\hline
\end{tabular}

\subsubsection{Light Water Reactor Mixed Oxide (LWR MOX) Fuel Assembly}

The calculations for the light water reactor configuration with MOX fuel are carried out only on fuel assembly level like it is standard in solid fueled reactor systems for the preparation of the cross sections for the following full core calculations. The fuel assembly model is following the OECD/NEA AND U.S. NRC PWR MOX/UO2 CORE TRANSIENT BENCHMARK [34] definition. 
The MOX fuel assembly consists of three different types of pins using 2.5\% (MOX 1), 3\% (MOX 2) and $5 \% \mathrm{Pu}$ fiss (MOX 3) content, and WABA-wet annular burnable absorber in the guide tubes.

The fuel assembly consists of a 17 by 17 arrangement with 264 fuel pins (see Table 2), 24 guide tubes, and one instrumentation tube. The geometric arrangement of the HELIOS model is given in Figure 5. The average $\mathrm{Pu}_{\text {fiss }}$ content in the fuel assembly is calculated to $4.3 \% \mathrm{Pu}_{\text {fiss }}$ using for this study reactor grade plutonium and a fuel assembly burnup of $50 \mathrm{GWd} / \mathrm{tHM}$ at a power of $37.11 \mathrm{~W} / \mathrm{g}$.

Table 2. Basic geometric data of the light water reactor mixed oxide (LWR MOX) fuel assembly.

\begin{tabular}{ccc}
\hline Component & Dimension & Unit \\
\hline Outer pin diameter & 9.166 & $\mathrm{~mm}$ \\
Cladding thickness & 0.573 & $\mathrm{~mm}$ \\
Pin pitch & 12.6 & $\mathrm{~mm}$ \\
Assembly pitch & 21.42 & $\mathrm{~cm}$ \\
Fuel density & 10.41 & $\mathrm{~g} / \mathrm{cm}^{3}$ \\
\hline
\end{tabular}

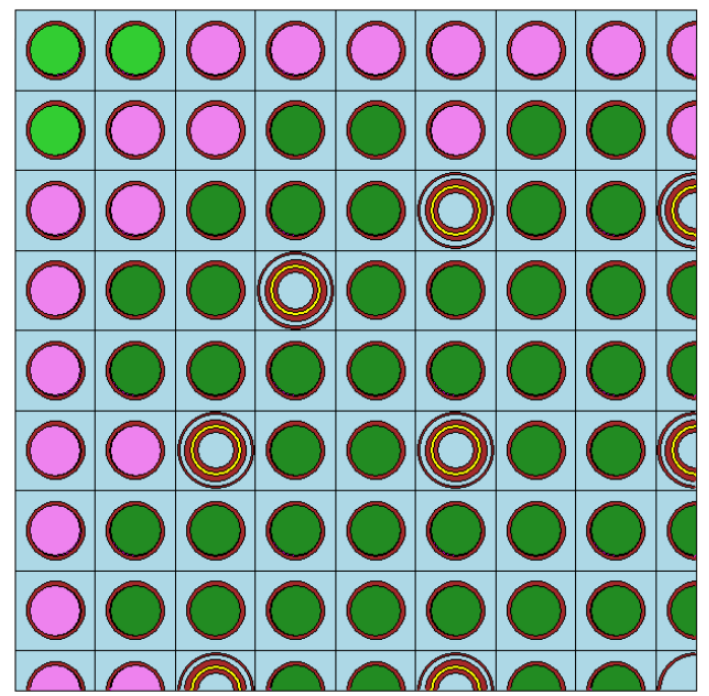

$$
\begin{aligned}
& \sqcup Г \mathrm{H}_{2} \mathrm{O} \\
& \text {-Г мох1 } \\
& \sqcup \Gamma \text { мох2 } \\
& \text { - Г мохз } \\
& \lrcorner Г \text { WABA } \\
& \text { घᄃ } \mathrm{zr}
\end{aligned}
$$

Figure 5. 1/4 of the light water reactor mixed oxide (LWR MOX) fuel assembly following the OECD/NEA AND U.S. NRC PWR MOX/UO2 CORE TRANSIENT BENCHMARK geometry.

\subsection{Calculation Tool and Material}

For all comparison calculations, the HELIOS 2.1 code has been used. The code is a 2D spectral code with wide unstructured mesh capabilities and a transport solver, based on the collision probability method [35]. The used libraries are the code internal 177 energy group library for the LWR and Sodium Cooled Fast Reactor (SFR) calculations and the 47 energy group library [28] for the MSR calculation (due to the significantly higher number of required calculations). The library id based on ENDF/B VII. Due to the characteristics of HELIOS, some approximations have to be accepted for the MSR and the fast reactor application. There is no fuel salt movement, thus an undesired burnup distribution arises during one calculation cycle. The materials are only re-distributed when a new user input is defined by the PYTHON script.

The HELIOS package has been developed as LWR code and a LWR spectrum is used for the weighting of the master libraries inside each energy group. A significant improvement has been observed for the use of HELIOS 2 with the cross section set based on ENDF/B VII. Comparisons to SERPENT on the isotope accumulation during the burnup in a fast reactor configuration using different HELIOS libraries have shown good agreement for the major isotopes [36]. Additionally, different older versions of the HELIOS 1 code have been used in the EVOL benchmark calculations for 
MSFR [37] and in the benchmark calculations in the ESNII+ project for SFR [38]. In both benchmark calculations the results were on a comparable level to the other applied codes. No major systematic discrepancies have been observed. The approximations and the use of the HELIOS code package seem to be adequate for this kind of cross over investigation for different reactors with significantly different neutron spectra.

The used TRU isotopic vector (see Table 3 ) is configured in the case of burning of $4 \%$ enriched uranium oxide (UOX) fuel in a LWR with $50 \mathrm{GWd} / \mathrm{tHM}$ burnup. The fuel cycle times are 5 years storage before reprocessing and 2 years until reuse in the reactor.

Table 3. Pu vector from $4 \%$ enriched uranium oxide (UOX) fuel with $50 \mathrm{GWd} / \mathrm{tHM}$ burnup. 5 years storage before reprocessing and 2 years until reuse in the reactor.

\begin{tabular}{ccc}
\hline Isotope & Content & Unit \\
\hline $\mathrm{Pu}-238$ & 2.62 & $\%$ \\
$\mathrm{Pu}-239$ & 54.43 & $\%$ \\
$\mathrm{Pu}-240$ & 23.70 & $\%$ \\
$\mathrm{Pu}-241$ & 11.28 & $\%$ \\
$\mathrm{Pu}-242$ & 6.83 & $\%$ \\
$\mathrm{Am}-241$ & 1.14 & $\%$ \\
\hline
\end{tabular}

\subsection{Results and Discussion}

The results presented in Table 4 demonstrate efficiency of the molten salt fast reactors as transmuter in comparison with a sodium cooled fast reactor and a thermal light water reactor with MOX fuel. The Pu reduction rate depends here only on the operation time and the remaining rest of fuel at the end of the operation time. The rest after 60 and 80 years is almost identical. However, this remaining fuel salt with the rest of the plutonium could be either used in a follow up machine, or a twofold lifecycle could be applied with a deep burn phase in the last years of operation [13,14,29] to reduce the TRU amount in the end of life (EOL) core. The results for the LWR and for the SFR demonstrate the limits given by the solid fuel. In current types of reactors this solid fuel cannot be produced in a fertile free configuration. Consequently, the MOX fuel used in these reactors leads to the breeding of new, in the view of Pu burning, undesired plutonium. The energy produced during the burnup cycle using the inserted plutonium is in all cases in the same range, but the plutonium burning is comparably low. This can be observed for the LWR where the Pu amount is reduced by only $36 \%$. The Pu burning in MOX fuels in LWR is currently only operated in a single step. Generally, a second step could be possible, but no real closed fuel cycle operation with multiple recycling. The reason for this limitation is given by the degradation of the Pu vector during Pu burning in a LWR spectrum, se the discussion of the EOL Pu vector below.

Table 4. Pu vector at end of life (EOL) and Pu burning rate for different reactor types. Molten salt fast reactor: MSFR; light water reactor mixed oxide: LWR MOX; sodium Cooled Fast Reactor: SFR.

\begin{tabular}{|c|c|c|c|c|c|c|}
\hline \multirow{2}{*}{$\begin{array}{c}\text { Reactor type } \\
\text { Operational parameter }\end{array}$} & \multicolumn{2}{|c|}{ MSFR } & \multirow{2}{*}{$\begin{array}{c}\text { LWR MOX assembly } \\
4.3 \% \mathrm{Pu}_{\text {fiss }}\end{array}$} & \multicolumn{3}{|c|}{ SFR assemblies } \\
\hline & 60 years & 80 years & & $18.3 \%$ & $22.4 \%$ & $26.9 \%$ \\
\hline $\mathrm{Pu}-238$ & $3.9 \%$ & $3.9 \%$ & $0.7 \%$ & $1.4 \%$ & $1.7 \%$ & $1.9 \%$ \\
\hline Pu-239 & $22.4 \%$ & $22.7 \%$ & $45.5 \%$ & $54.8 \%$ & $52.1 \%$ & $49.8 \%$ \\
\hline $\mathrm{Pu}-241$ & $10.0 \%$ & $9.9 \%$ & $17.6 \%$ & $5.5 \%$ & $6.0 \%$ & $6.5 \%$ \\
\hline $\mathrm{Pu}-242$ & $17.0 \%$ & $16.9 \%$ & $6.1 \%$ & $6.6 \%$ & $7.6 \%$ & $8.3 \%$ \\
\hline Pu burning rate relative & $83.9 \%$ & $87.2 \%$ & $35.9 \%$ & $11.9 \%$ & $21.8 \%$ & $28.1 \%$ \\
\hline Fuel target burnup & - & - & $50 \mathrm{GWd} / \mathrm{tHM}$ & $200 \mathrm{GWd} / \mathrm{tHM}$ & $200 \mathrm{GWd} / \mathrm{tHM}$ & $200 \mathrm{GWd} / \mathrm{tHM}$ \\
\hline
\end{tabular}

In the studied SFR configuration, the Pu reduction is even worse. This should not wonder at all, since the EFR has not been designed to burn Pu, rather the design target was breeding of fresh fissile 
material. Depending on the initial Pu content the Pu reduction varies. The inner fuel with the low $\mathrm{Pu}$ content leads only to a minor reduction since the breeding of fresh $\mathrm{Pu}$ almost compensates the burning. The increase of the initial $\mathrm{Pu}$ content improves the $\mathrm{Pu}$ reduction slowly-the configuration comes closer to a burner configuration. The results for the lattice calculation with the $26.9 \%$ initial $\mathrm{Pu}$ content should be taken with care due to the very high $\mathrm{k}_{\text {inf. }}$. In the real reactor configuration, these fuel assemblies act as a strong neutron source for their surrounding assemblies leading to breeding there. The initial Pu content is comparable to the fuel assemblies used in CAPRA, but there $\sim 1 / 3$ of the pins has been replaced by diluents to reduce the criticality. In the EFR full core configuration the breeding gain has been planned to -0.2 in the core only and +0.02 in the whole system including the blanket assemblies [30]. In general, it has to be kept in mind, that the typical SFR using solid fuel is foreseen to be operated in a closed fuel cycle mode. The flexibility of SFRs opens a whole range of operational modes-breeder, iso-breeder or burner, just depending on the core design [39]. However, the efficiency even of the burner configuration is limited since for the closed fuel cycle operation an acceptable $\mathrm{Pu}$ vector has to be preserved. This is usually achieved by breeding of fresh Pu. If this is not the case, the closed fuel cycle operation will not be possible as discovered during the CAPRA studies by Wiese, see discussion below. However, the closed fuel cycle which is foreseen to be established in the SFR operation has some important drawback on the time schedules. The fuel requires significant time to cool down before the reprocessing can be performed, at least as long as the reprocessing is performed in the traditional aqueous scheme. The reprocessing has to be followed by a new production of solid fuel which than can be inserted into the reactor. For the whole process a time period of 5 to 10 years out of the reactor has to be estimated for. Consequently, the fuel has to be handled out of the reactor several times in the SFR fuel cycle. This is in strong contrast to the MSR where the fuel is kept inside the system until it is burnt.

The extremely high reductions of the Pu amount in the MSFR cases are a result of the fertile free configuration. Thus, energy is only produced from plutonium and no new plutonium is produced via breeding. The longer the machine operates, the better the Pu reduction is since the unloading mass is in all cases almost identical-the core is after 60 years of operation almost in equilibrium. In contrast the inserted mass increases slightly with every operation year due to the small built up of higher TRUs. The required solution capacity of the salt for the required TRU load can be assured over the whole operational span for the used salt defined in the MOSART project.

However, if breeding is welcome in the fuel cycle strategy, it would be possible in MSFR, too due the already mentioned high flexibility of MSRs. The big advantage of the MSFR in this case would be the elimination of the multi recycling and the solid fuel production. Additionally, no Pu, neither the inserted one, nor the bred one will come out of the reactor. Remember the statement: When the plutonium or other fissile material is once put into a MSR system it is not necessary to separate the material in any of the steps of the burning operation anymore.

The plutonium vector at EOL is an important indicator for the evaluation of the nuclear security. The higher the share of ${ }^{239} \mathrm{Pu}$ in the fuel at EOL is, the higher the proliferation risk is. The highest ${ }^{239} \mathrm{Pu}$ share at EOL is available in the SFR, since the breeding of new ${ }^{239} \mathrm{Pu}$ takes place most efficiently. The breeding process is slowed down with increasing initial $\mathrm{Pu}$ content. This fact has been applied and optimized in the CAPRA project by the design of fuel assemblies with very high initial Pu content and distributed so-called diluents made of steel [8]. In LWRs, almost only the fissile uneven Pu isotopes are brunt. Consequently, the ${ }^{239} \mathrm{Pu}$ share in the Pu vector at EOL is lower than in the fast reactor even if some new ${ }^{239} \mathrm{Pu}$ is bred from the ${ }^{238} \mathrm{U}$ matrix. In the MSFR, all Pu isotopes have almost reached their asymptotic values due to the long operational span. Thus the vector does not change very much between the configuration after 60 and 80 years. The ${ }^{239} \mathrm{Pu}$ content is in both cases much lower than in the solid fueled systems. However, another important point form the point of view of security is that the TRUs are newer required to be separated during the operation of a MSFR. 
2.4. Consommation Accrue de Plutonium dans les Réacteurs à Neutrons Rapides/Consommation Accrue des Dechets dans les Reacteurs RApides (CAPRA/CADRA) Project Results

The CAPRA core design has been developed in the beginning of the $90 \mathrm{~s}$. The design is based on the Superhénix arrangement, since in a first attempt it had been the plan to adopt Superphénix for the burning of plutonium. Thus the power is given to $1500 \mathrm{MWe}$ or $3600 \mathrm{MWth}$ [40]. The design problems are described by Broeders et al. [41]: "At present the Pu content is limited to $45 \%$ to remain compatible with the existing manufacturing processes. These high plutonium contents require high dilutions of the fuel in the core. These are obtained by a three-level dilution strategy: small diameter fuel pins with hollow fuel pellets, heterogeneous fuel assemblies containing about 30 'fuel-free' pins and a heterogeneous core layout with a number of 'fuel-free' sub-assemblies. A main problem for the core-layout is the high burnup reactivity, compared to existing LMFRs". The burnup for the study has been fixed to $200 \mathrm{GWd} / \mathrm{tHM}$ [8] or to $150 \mathrm{GWd} / \mathrm{tHM}$ [33]. The reactivity loss over the cycle of $285 \mathrm{~d}$ has been calculated to $\sim 9000 \mathrm{pcm}$ which corresponds to more than $27 \$$. In the study the $\mathrm{Pu}$ burning rat has been determined to $74.2 \mathrm{~kg} / \mathrm{TW}_{\mathrm{e}} \mathrm{h}\left(\hat{=} 30.9 \mathrm{~kg} / \mathrm{TW}_{\mathrm{th}} \mathrm{h}\right)$ with a minor actinide production of $9.7 \mathrm{~kg} / \mathrm{TW}_{\mathrm{e}} \mathrm{h}$ [8]. The results have been confirmed by Broeders et al.: "Accepting the above enrichment constraint [45\%], an incineration rate of roughly $70 \mathrm{~kg}(\mathrm{Pu}) / \mathrm{TWh}(\mathrm{e})$ or $600 \mathrm{~kg}$ $(\mathrm{Pu}) / \mathrm{GWa}(\mathrm{e})\left[\hat{=} 28.5 \mathrm{~kg} / \mathrm{TW}_{\mathrm{th}} \mathrm{h}\right.$ ] was obtained for a CAPRA-type reactor with MOX fuel" [41]. In a later study the plutonium burning in a Thorium based core has been calculated to $82 \mathrm{~kg} / \mathrm{TW}_{\mathrm{e}} \mathrm{h}$ but with a production of a significant amount of U-233 [33].

During the studies at FZK some additional effects of the high Pu content have been discovered: "It turns out that for the CAPRA reactor with (U,Pu)-MOX fuel the upper limit of $\mathrm{Pu} /(\mathrm{U}+\mathrm{Pu}) \approx 0.45$ works against quantitative recycling of burner $\mathrm{Pu}$ because of its quality decreasing with continued recycling" [42]. Consequently, this leads to the following conclusion: "CAPRA burner turns out to be a high-grade consumer of 'good and bad quality' $\mathrm{Pu}$, leaving behind $\mathrm{Pu}$ which is deteriorated and proliferation resistant. In equilibrium, $58 \%$ of $\mathrm{Pu}$ from reprocessing of spent CAPRA fuel has to be ultimate excluded from recycling" [42]. Thus, the CAPRA 4/94 core is not sustainable. An unlimited reprocessing cannot be achieved since the $\mathrm{Pu}$ quality is rapidly degrading — this can be evaluated as good for the proliferation resistance, but not for the sustainable burning of plutonium. The degradation of the plutonium vector will lead to a configuration with which it will not be possible to achieve criticality in the follow up core.

CADRA Dedicated fast reactor with fertile free core with very low TRU mass in core $(8 \mathrm{t}, 88 \%$ $\mathrm{Pu}, 8 \% \mathrm{Am}, 4 \% \mathrm{Cm}$ ) requires a high recycle mass flow. In this kind of reactors it is promised to achieve of a PU burning rate of $99 \mathrm{~kg} / \mathrm{TW}_{\mathrm{e}} \mathrm{h}$ and a MA burning rate of $7 \mathrm{~kg} / \mathrm{TW}_{\mathrm{e}} \mathrm{h}$. [43] These two value sum to the theoretically possible value of $106 \mathrm{~kg} / \mathrm{TW}_{\mathrm{e}} \mathrm{h}$, or $\sim 44 \mathrm{~kg} / \mathrm{TW}_{\mathrm{th}} \mathrm{h}$. The numbers for the specific TRU vector in this study are theoretical numbers without core design and feasibility of fuel production. The described core contains a very low Pu mass, but a very high Pu content and a cycle length of $480 \mathrm{~d}$ which will lead to a tremendous reactivity loss over cycle in a solid fuelled reactor. The problem of Pu degradation described above has to be expected for these systems, too. Regarding dedicated cores, the experts of the FZK, now KIT, found the following burning rates to be reasonably achievable in a specially designed dedicated LMFR core for transmutation: "The following rates may be achieved: plutonium; $600 \mathrm{~kg} / \mathrm{GWea}\left(\hat{=} 28.5 \mathrm{~kg} / \mathrm{TW}_{\mathrm{th}} \mathrm{h}\right), \mathrm{Np} 237 ; 140 \mathrm{~kg} / \mathrm{GWea}\left(\hat{=} 6.7 \mathrm{~kg} / \mathrm{TW}_{\mathrm{th}} \mathrm{h}\right)$, and Am 241; $80 \mathrm{~kg} / \mathrm{GWea}\left(\hat{=} 3.8 \mathrm{~kg} / \mathrm{TW}_{\mathrm{th}} . \mathrm{h}\right)$ " [41]. However, it has to be kept in mind that the results for CADRA as well as for CAPRA would only be achievable with a multiple recycling strategy and thus multiple reprocessing and fuel production which will be a growing challenge in time as well as in complexity with increasing number of steps.

Other innovative systems following the ideas discussed in CADRA using multiple recycling are under discussion and development. Some of them have been collected in the framework of INPRO of the IAEA [44] like the ABR [45] (advanced burner reactor) of the Global Nuclear Energy Partnership (GENEP) program of the United States or the accelerator driven system (ADS) [46] under development in several framework programs of the European community. The systems are discussed 
under the view of special fertile free fuels following the findings of CADRA like inert matrix fuel, rock-like oxide fuel, U-free metal fuel. Additionally, there are some commercial developments like PRISM [47] developed by GE Hitachi and RBWR [48,49] under development at Hitachi.

In general it has to be kept in mind for solid fueled reactors: "Fertile free fuel causes a high reactivity loss over the cycle due to the absence of a fertile material, since no breeding of new fissile material occurs ... In fertile free fuel this excess reactivity has to be high to reach an acceptable long cycle time when no breeding takes place to produce fresh fissile material during the cycle like it is done in traditional fast reactor designs. Two choices are possible for the designer. On the one hand it would be possible to reduce the cycle time this results in reduced operational performance and prolonged out of operation time of the reactor ... On the other hand it is possible to use a high excess reactivity which requires a strong control system with effective single control elements to compensate the excess reactivity at begin of cycle or a very high number of costly and complex control elements which have to be placed in the narrow space above the core" [14].

The results for the Pu reduction planned to be achieved in the CAPRA cores $\left(\sim 30 \mathrm{~kg} / \mathrm{TW}_{\mathrm{th}} \mathrm{h}\right) \mathrm{can}$ be exceeded in a molten salt fast reactor applying a fertile free configuration with a burning rate of $\sim 43 \mathrm{~kg} / \mathrm{TW}_{\mathrm{th}} \mathrm{h}$. This value is within the expected accuracy to be seen as identical with the promised values of CADRA for the fertile free system. The exact theoretical number depends on the exact fuel configuration since the energy per fission is slightly isotope dependent.

The often discussed possibility of the Pu burning in MOX fuels in LWRs is real solution. The use of one cycle MOX in a LWR does not lead to a long term solution of the plutonium problem. Multiple recycling could achieve a balanced state, but only after several decades [50].

\section{Conclusions}

Pu burning will be an essential point to increase the sustainability of LWR operation for the future. At least as long as the closed fuel cycle option with massive use of fast reactors is not established as a standard. The Pu burning could avoid the accumulation of $\mathrm{Pu}$ in the final disposal. With this strategy the sometimes postulated $\mathrm{Pu}$ mine will be effectively avoided, even after the self-protection standard of the nuclear fuel has decayed.

MSRs offer very special features which make these kinds of reactors very much suitable for efficient burning of plutonium. One major key is the possibility of different operational modes based on fertile free fuel compositions. On the one hand this is possible due to the excellent inherent safety effects of MSFRs which are given due to the unity of coolant and fuel. On the other hand due to the high flexibility in the use of different fissile materials or qualities of the fissile material like it has been demonstrated in the MSRE by the smooth transition for ${ }^{235} \mathrm{U}$ fuel to ${ }^{233} \mathrm{U}$ fuel. The general operation management can be based on the strategy that the plutonium and other fissile materials which are put into the reactor core come never out anymore. In addition, this strategy is excellent from the point of view of nuclear security.

The comparison of the neutronic results with current state reactors like LWR with MOX and SFR shows the advantage of the MSFR for the Pu reduction. The main reason is the possibility of a fertile free core configuration. The detailed comparison with one of the first promising coordinated scientific project on the burning of TRU isotopes and plutonium demonstrates that the simulated MSFR could outperform the results gained in the CAPRA project from neutronic point of view. The CAPRA results of Pu burning rates of $28.5 \mathrm{~kg} / \mathrm{TW}_{\text {th }}$ h to $30.9 \mathrm{~kg} / \mathrm{TW}_{\text {th }} \mathrm{h}$ can be exceeded by the fertile free configuration which enables to achieve the theoretical limit value of $\sim 43 \mathrm{~kg} / \mathrm{TW}_{\mathrm{th}} \mathrm{h}$. This is the limit given by the average fission energy content of the different Pu isotopes. In the CADRA project it had been projected to achieve this limit, too by the application of a fertile free fuel configuration. However, it is from economic as well as from safety point of view almost impossible to operate a solid fueled critical reactor with a fertile free fuel configuration.

However, there is another nice effect due to the flexibility of MSFRs. If breeding is welcome in the fuel cycle strategy, it would be possible in MSFR, too. The big advantage of the MSFR in this 
case would be the elimination of the multi recycling and the solid fuel production. Additionally, no $\mathrm{Pu}$, neither the inserted one, nor the bred one will come out of the reactor. Remember the statement: When the plutonium or other fissile material is once put into a molten salt reactor system it is not necessary to separate the material in any of the steps of the burning operation anymore.

\section{Outlook}

Ideally, the idea of efficient TRU burning in a MSFR should end up in "our dream", an international endeavor carried by all countries with national strategies which do not envisage an extensive use of the fast reactor technology for energy production. This would be a way to stop the worldwide TRU accumulation problem in the future and thus to improve sustainability of LWR operation. The international endeavor for burning TRUs would be in our view the preferred solution compared to the transfer of the TRUs inside the burnt fuel into a final disposal (direct disposal). The burning of TRU is the only way to exclude misuse and theft of plutonium on the long term. We are not alone with this view; see the statement of Oi in the IAEA bulletin in 1998. The statement has already been given as opener. It is repeated here, because of its future relevance: "Within 200 years, the protection afforded by intense radioactivity (spent fuel standard) will disappear as the result of the decay of most radioactive nuclides. If the spent fuel is buried in a geological formation, it might be regarded as a potential 'plutonium mine' meaning that at some later point in time the buried plutonium could be mined and extracted" [2]. The application of a strategy to burn the existing plutonium efficiently would increase the sustainability of LWR operation by:

- Reducing the waste amount since Pu is the major volumetric challenge of P\&T.

- Elimination the effects of the plutonium which has been produced during LWR operation, we should burn what we have built or produced. We brought the plutonium into the world and we should be able to clear it away efficiently.

- Elimination of the risk of misuse and theft of Pu from the burnt fuel after the self-protection has disappeared. There should be a better solution than to dig it only.

- Using the large energy amount latent in the plutonium to create electricity while we clear it away.

In an ideal case this objectives should be achieved:

- Without extensive multi-recycling, let's limit the reprocessing to one cycle, avoiding the solid fuel production at all and significantly reduce the transports which are one of the most vulnerable points which can develop to a condensation point of public protests like it appeared in Germany.

- Without separation of the plutonium in the several stages of the multi-recycling, what is once put into the reactor will stay there until it is burnt.

- Without installation of a classical fast reactor park for electricity production, thus without the multi-recycling and the often cited entering into so-call plutonium economy which could lead to public protests, too.

In our view, the general aim of all kinds of nuclear reactor operation should be to close the lifecycle of the plutonium from the cradle to the grave.

Author Contributions: Study design, calculations and writing: Bruno Merk; calculations and writing: Dzianis Litskevich.

Conflicts of Interest: The authors declare no conflict of interest.

\section{References}

1. Arkhipov, V. Future nuclear energy systems: Generating electricity, burning wastes. IAEA Bulletin, 39/2/1997, 1997. Available online: https://www.iaea.org/sites/default/files/publications/magazines/ bulletin/bull39-2/39204783033.pdf (accessed on 27 February 2015). 
2. Oi, N. Plutonium Challenges-Changing Dimensions of Global Cooperation, IAEA Bulletin 40-1, Comparing Energy Options, 1998. Available online: http://www.iaea.org/Publications/Magazines/ Bulletin/Bull401/article3.html (accessed on 26 March 2015).

3. Chow, B.G. Limiting the Accumulation of Weapon-Usable Plutonium, RAND Testimony, CT-177, 1994. Available online: http://www.rand.org/content/dam/rand/pubs/.../CT117.pdf (accessed on 23 January 2015).

4. Renn, O. (Hrsg.). Partitionierung und Transmutation. Forschung-Entwicklung-Gesellschaftliche Implikationen (acatech STUDIE), München: Herbert Utz Verlag 2014. Available online: http://www.acatech.de/fileadmin/user_upload/Baumstruktur_nach_Website/Acatech/root/de/Projekte/ Laufende_Projekte/Transmutation/PuT_Studie_komplett_2013-10-22.pdf (accessed on 27 November 2014). (In German)

5. Weitze, M.-D. Partitionierung und Transmutation nuklearer Abfälle. Chancen und Risiken in Forschung und Anwendung (acatech POSITION), München: Herbert Utz Verlag 2014. Available online: http://www.acatech.de/de/publikationen/stellungnahmen/acatech/detail/artikel/partitionierung-undtransmutation-nuklearer-abfaelle-chancen-und-risiken-in-forschung-und-anwend.html (accessed on 6 March 2015). (In German)

6. Merz, E.R. Introduction to NATO advanced research workshop. In Advanced Nuclear Systems Consuming Excess Plutonium, Proceedings of the Advanced Research Workshop on Advanced Nuclear Systems Consuming Excess Plutonium, Moscow, Russia, 13-16 October 1996; Merz, E.R., Walter, C.R., Eds.; Springer: Amsterdam, The Netherlands, 1997; Volume 15.

7. Puthiyavinayagam, P. Progress in Fast Reactor Programme of India: April 2014-March 2015. In Proceedings of the 48th Annual Meeting of TWGFR, IAEA IPPE, Obninsk, Russia, 25-29 May 2015.

8. Languille, A.; Gamier, J.C.; Lo Pinto, P.; Na, B.C.; Verrier, D.; Deplaix, J.; et al. CAPRA core studies. The oxide reference option. In Proceedings of the International Conference on Evaluation of Emerging Nuclear Fuel Cycle Systems, Versailles, France, 11-14 September 1995; pp. 874-881.

9. Gat, U.; Engel, J.R.; Dodds, H.L. Molten Salt Reactors for Burning Dismantled Weapons Fuel, Technical Note. Nucl. Technol. 1992, 100, 390-394.

10. MacPherson, H.G. The Molten Salt Reactor Adventure. Nucl. Sci. Eng. 1985, 90, 374-380.

11. Engel, J.R.; Grimes, W.R.; Rhoades, W.A.; Dearing, J.F. Molten-Salt Reactors for Efficient Nuclear Fuel Utilization without Plutonium Separation, ORNL/TM-6413, August 1978. Available online: http://web.ornl.gov/info/reports/1978/3445603227167.pdf (accessed on 15 July 2015).

12. Engel, J.R.; Grimes, W.R.; Rhoades, W.A.; Dearing, J.F. Molten-Salt Reactors for Efficient Nuclear Fuel Utilization without Plutonium Separation. Nucl. Technol. 1979, 46, 30-43.

13. Merk, B.; Rohde, U.; Scholl, S. The Molten Salt Fast Reactor as Transmutation System. In Proceedings of the International Conference on Fast Reactors and Related Fuel Cycles: Safe Technologies and Sustainable Scenarios (FR13), Paris, France, 4-7 March 2013.

14. Merk, B.; Rohde, U.; Glivici-Cotruta, V.; Litskevich, D.; Scholl, S. On the Molten Salt Fast Reactor for Applying an Idealized Transmutation Scenario for the Nuclear Phase Out. PLoS ONE 2014, 9. [CrossRef] [PubMed]

15. Alekseev, P.N. Utilization of excess Plutonium in molten salt reactors. In Advanced Nuclear Systems Consuming Excess Plutonium, Proceedings of the Advanced Research Workshop on Advanced Nuclear Systems Consuming Excess Plutonium, Moscow, Russia, 13-16 October 1996; Merz, E.R., Walter, C.R., Eds.; Springer: Amsterdam, The Netherlands, 1997.

16. Kim, T.K.; Taiwo, T.A.; Wigeland, R.A.; Dixon, B.W.; Gehin, J.C.; Todosow, M. Mass Flow Data Comparison for Comprehensive Fuel Cycle Options. In Proceedings of the Actinide and Fission Product Partitioning and Transmutation Thirteenth Information Exchange Meeting, Seoul, Korea, 23-26 September 2014.

17. Renault, C.; Delpech, M. MOST Final Report; EURATOM Contract Number FIKI-CT-2001-20183; European Commission: Brussels, Belgium, 2005.

18. Mathieu, L.; Heuer, D.; Billebaud, A.; Brissot, R.; Garzenne, C.; Le Brun, C.; Lecarpentier, D.; Liatard, E.; Loiseaux, J.-M.; Meplan, O.; et al. Proposal for a Simplified Thorium Molten Salt Reactor. In Proceedings of GLOBAL 2005, Tsukuba, Japan, 9-13 October 2005; pp. 9-13. 
19. EVOL-Evaluation and Viability of Liquid Fuel Fast Reactor System. Available online: http://cordis.europa.eu/search/index.cfm?fuseaction=proj.document\&PJ_LANG=EN\&PJ_RCN= 11669355\&pid=5 (accessed on 18 October 2012).

20. Renault, C.; Guérard, C. The Molten Salt Reactor (MSR). GIF System Development Progress Status. In Proceedings of the 4th INPRO-GIF Interface Meeting, Vienna, Austria, 1-3 March 2010.

21. Merle-Lucotte, E.; Heuer, D.; Allibert, M.; Brovchenko, M.; Capellan, N.; Ghetta, V. Launching the thorium cycle with molten salt reactor. In Proceedings of the International Congress on Advances in Nuclear Power Plants (ICAPP 2011), Nice, France, 2-5 May 2011.

22. Ingatiev, V.; Feynberg, O.; Merzlyakov, A.; Surenkov, A.; Zagnitko, A.; Afonichkin, V.; Bovet, A.; Khokhlov, V.; Subbotin, V.; Fazilov, R.; et al. Progress in Development of MOSART Concept with Th Support. In Proceedings of the International Congress on Advances in Nuclear Power Plants (ICAPP'12), Chicago, IL, USA, 24-28 June 2012.

23. Ignatiev, V.; Feynberg, O.; Gnidoi, I.; Merzlyakov, A.; Smirnov, V.; Surenkov, A.; Tretiakov, I.; Zakirov, R. Progress in Development of $\mathrm{Li}, \mathrm{Be}, \mathrm{Na} / \mathrm{F}$ Molten Salt Actinide Recycler \& Transmuter Concept. In Proceedings of the International Congress on Advances in Nuclear Power Plants (ICAPP) 2007, Nice, France, 13-18 May 2007.

24. Ignatiev, V.; Feynberg, O.; Gnidoi, I.; Merzlyakov, A.; Surenkov, A.; Uglov, V.; Zagnitko, A.; Subbotin, V.; Sannikov, I.; Toropov, A.; et al. Molten salt actinide recycler and transforming system without and with Th-U support: Fuel cycle flexibility and key material properties. Ann. Nucl. Energy 2014, 64, 408-420. [CrossRef]

25. Ignatiev, V.; Feynberg, O.; Gnidoi, I.; Konakov, S.; Kormilitsyn, M.; Merzliakov, A.; Surenkov, A.; Uglov, V.; Zagnitko, A. MARS: Story on Molten Salt Actinide Recycler and Transmuter Development by Rosatom in Co-operation with Euratom. In Proceedings of the Actinide and Fission Product Partitioning and Transmutation Thirteenth Information Exchange Meeting, Seoul, Korea, 23-26 September 2014.

26. The raw data of the calculations and the used PYTHON script are stored at the HZDR library. Available online: https:/ / www.hzdr.de/db/!FzrTools.Archiving.ArchiveInfos?pNid=223\&pId=1548 (accessed on 15 July 2015).

27. Brovchenko, M.; Merle-Lucotte, E.; Rouch, H.; Alcaro, F.; Aufiero, M.; Cammi, A.; Dulla, S.; Feynberg, O.; Firma, L.; Geoffroy, O.; et al. Evaluation and Viability of Liquid Fuel Fast Reactor System EVOL, Optimization of the pre-conceptual design of the MSFR, DELIVERABLE D 2.2. Available online: http://www.janleenkloosterman.nl/reports/evol_d22_201309.pdf (accessed on 30 October 2015).

28. Wemple, C.A.; Simeonow, T.; Rhodes, J.D., III. HELIOS-2 Methods Version 2.1; SSP-11/452 Rev 1, Studsvik Scandpower, Inc.: Idaho Falls, ID, USA; 16, December, 2011.

29. Merk, B.; Litskevich, D. Transmutation of all German Transuranium under Nuclear Phase out conditions-Is this Feasible from Neutronic Point of View? PLoS One under review.

30. IAEA Fast Reactor Database-2006 Update. IAEA TECDOC 1531. Available online: http:/ / www-pub.iaea. org/books/IAEABooks/7581/Fast-Reactor-Database-2006-Update (accessed on 27 October 2015).

31. Waltar, A.E.; Reynolds, A.B. Fast Breeder Reactors; Pergamon Press: New York, NY, USA, 1981.

32. Pay, A.; Francillon, E.; Steinmetz, B.; Barnes, D.; Meda, N. European Fast Reactor (EFR) Fuel Element Design. In Proceedings of the 10th International Conference on Structural Mechanics in Reactor Technology, Anaheim, CA, USA, 14-18 August 1989.

33. Salvatores, M.; Delpech, M. Advanced systems for Plutonium utilization, published in Advanced nuclear systems consuming excess plutonium. In Advanced Nuclear Systems Consuming Excess Plutonium, Proceedings of the Advanced Research Workshop on Advanced Nuclear Systems Consuming Excess Plutonium, Moscow, Russia, 13-16 October 1996; Merz, E.R., Walter, C.R., Eds.; Springer: Amsterdam, The Netherlands, 1997.

34. Kozlowski, T.; Downar, T.J. OECD/NEA AND U.S. NRC PWR MOX/UO2 CORE TRANSIENT BENCHMARK, OECD Nuclear Energy Agency Nuclear Science Committee, Final Specifications, Revision 2 December 2003. Available online: https://www.oecd-nea.org/science/wprs/MOX-UOX-transients/ (accessed on 27 October 2015).

35. Villarino, E.A.; Stammler, R.J.J.; Ferri, A.; Casal, J.J. HELIOS: Angularly dependent collision probabilities. Nucl. Sci. Eng. 1992, 112, 16-31. 
36. Rachamin, R.; Wemple, C.; Fridman, E. Neutronic analysis of SFR core with HELIOS-2, Serpent, and DYN3D codes. Ann. Nucl. Energy 2013, 55, 194-204. [CrossRef]

37. Brovchenko, M. Neutronic Benchmark of the Molten Salt Fast Reactor in the Frame of the EVOL and MARS Collaborative Projects. Prog. Nucl. Energy under review.

38. Mikityuk, K. Core Safety (ESNII + WP6). In Proceedings of the European Nuclear Gen II, III, IV Days, Brussels, Belgium, 17-19 March 2015.

39. Merk, B.; Stanculescu, A.; Chellapandi, P.; Hill, R. Progress in reliability of fast reactor operation and new trends to increased inherent safety. Appl. Energy 2015, 147. [CrossRef]

40. Rouault, J.; Garnier, J. C.; Languille, A.; Lo Pinto, P. The design of U-free large fast reactor cores. The CAPRA programme trends PHYSOR 96: Breakthrough of Nuclear Energy by Reactor Physics. In Proceedings of the International Conference on the Physics of Reactors, Mito, Japan, 16-20 September 1996.

41. Broeders, C.H.M.; Broeders, I.; Kessler, G.; Kiefhaber, E. Recent Neutron Physics Investigations on the Incineration of Plutonium and Other Transurania Isotopes. In Advanced Nuclear Systems Consuming Excess Plutonium, Proceedings of the Advanced Research Workshop on Advanced Nuclear Systems Consuming Excess Plutonium, Moscow, Russia, 13-16 October 1996; Merz, E.R., Walter, C.R., Eds.; Springer: Amsterdam, The Netherlands, 1997.

42. Wiese, H.W. Actinide transmutation properties of thermal and fast fission reactors including multiple recycling. J. Alloys Compd. 1998, 271-273, 522-529. [CrossRef]

43. Vasile, A.; Vambenepe, G.; Lefèvre, J.C.; Hesketh, K.; Mashek, W.; De Raedt, C.; Haas, D. The CAPRA-CADRA programme, ICONE 8. In Proceedings of the 8th International Conference on Nuclear Engineering, Baltimore, MD, USA, 2-6 April 2000.

44. Status and Trends of Nuclear Technologies. Report of the International Project on Innovative Nuclear Reactors and Fuel Cycles (INPRO). Available online: http://www-pub.iaea.org/MTCD/ publications/PDF/TE_1622_Web.pdf (accessed on 15 October 2015).

45. Global Nuclear Energy Partnership Technology Demonstration Program Dave Hill. Available online: http://www.mcs.anl.gov/events/workshops/nprcsafc/Presentations/NucPhysConf.pdf (accessed on 15 October 2015).

46. Knebel, J.; Eurotrans, I.P. A European Research Programme for the Transmutation of High Level Nuclear Waste in an Accelerator Driven System. Available online: https//www.oecd-nea.org/pt/docs / iem/lasvegas04/11_Session_V/S5_01.pdf (accessed on 15 October 2015).

47. PRISM: Technology to Power and Secure our Energy Future. Available online: http://gehitachiprism.com/ (accessed on 15 October 2015).

48. Yamashita, J.; Kawamura, F.; Mochida, T. Next-generation Nuclear Reactor Systems for Future Energy. Available online: http://www.hitachi.com/rev/pdf/2004/r2004_03_105.pdf (accessed on 15 October 2015).

49. Takeda, R.; Aoyama, M.; Moriwaki, M.; Uchikawa, S.; Yokomizo, O.; Ochiai, K. General Features of Resource-Renewable BWR (RBWR) and Scenario of Long-term Energy Supply. In Proceedings of the International Conference on Evaluation of Emerging Nuclear Fuel Cycle Systems (GLOBAL95), Versailles, France, 11-14 September 1995.

50. Kessler, G.; Kim, J.I.; Gompper, K. Wohin mit dem deutschen Plutonium. Int. Z. Kernenerg. 1999, 44, 156-164. (In German)

(C) 2015 by the authors; licensee MDPI, Basel, Switzerland. This article is an open access article distributed under the terms and conditions of the Creative Commons by Attribution (CC-BY) license (http://creativecommons.org/licenses/by/4.0/). 